\title{
Design of Beef Cattle Feeding System Based on Motion Controller
}

\author{
Xiao-Qiang $\mathrm{Wu}^{1, \mathrm{a}}$, Da-Peng $\mathrm{Liu}^{2, \mathrm{~b}}$ \\ ${ }^{1}$ Inner Mongolia University for the Nationalities, College of Mechanical Engineering, Tong Liao, \\ 028000, China; \\ ${ }^{2}$ NO.724 Research Institute under CSIC, Nanjing Jiangsu 210003, China; \\ awuxiaoqiang6006@163.com, 'liudapeng@163.com,
}

Keywords: Beef cattle, Automatic feeding, Control system.

\begin{abstract}
According to the traditional beef cattle feeding way of simple equipment, low labor efficiency, high production cost, a beef cattle automatic feeding system is designed based on motion controller. This system uses form of upper computer and lower computer, PC is for the overall planning and programming, and the parameter setting and display. Motion controller is for motion control. Because of the modular design, feeding quantity can be configured according to user needs. The accuracy of the experiment proves that the system is feasible, it can apply to automatic feeding beef cattle industry, it has a certain practical significance.
\end{abstract}

\section{Introduction}

With the deepening reform of animal husbandry continuously, beef cattle breeding occupies an increasingly large proportion in animal husbandry in our country. In recent years, China's beef cattle feeding grows quickly [1]. In beef cattle feeding process, concentrate and roughage is separately fed, which can further improve the yield of beef cattle breeding, in order to further improve the feeding level and narrow the gap with developed countries in the world, beef cattle production machinery has become an inevitable road [2]. The traditional way is to feed silage, hay, tank slag and feed separately [3]. The characteristics of the traditional way of feeding are: equipment investment is not large, keeping staff has the advantages of simple operation, low requirement of coarse fodder. But this way also has the following disadvantages: separate feeding may cause various feed intake of nutrients are not enough, which affects the growth of beef cattle, it requires a lot of manual operation, high labor cost, low production efficiency. It is unable to adapt to the rapid development of industry [4]. In order to change this situation, this paper designed a kind of automatic feeding system, feeding personnel through calculation and experience obtain reasonable values on the nutrient composition of beef cattle, automatic feeding system can feed automatically, instead of traditional labor, which can realize the mechanization and automation of beef cattle feeding.

\section{Hardware design}

Overall design. As shown in Figure 1, beef cattle automatic feeding system adopts open loop control, and modular design. The system consists of upper and lower computer, lower computer controls terminal feeding mechanism. The main terminal mechanism, as well automatic feeding device, is a feedstuff feeder. The feeder adopts Geneva wheel structure. As shown in Figure 2, the Geneva wheel feeder is mainly composed of a shell, Geneva wheel, shaft, hopper etc. The Geneva wheel structure can realize automatic feeding, and can also measure the number of the fodder. In the process of work, fodder is fed into the feed hopper, the wheel rotates to drive the fodder to feed, because of the volume of wheel tooth is certain, the number can be controlled according to the angle of rotation of the material. The feeding system falls the sum of the feeding amount, which equals to all alveolar volume between the feeder under the rotation of a circle. 


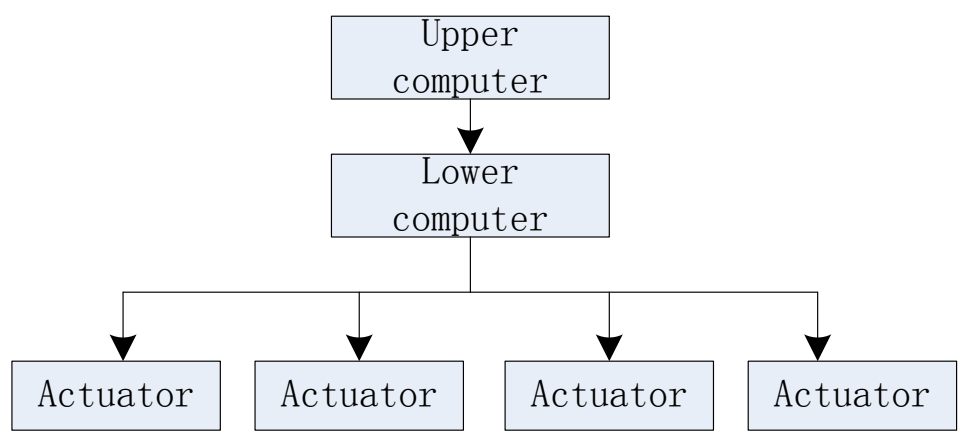

Figure 1.The feeding system structure

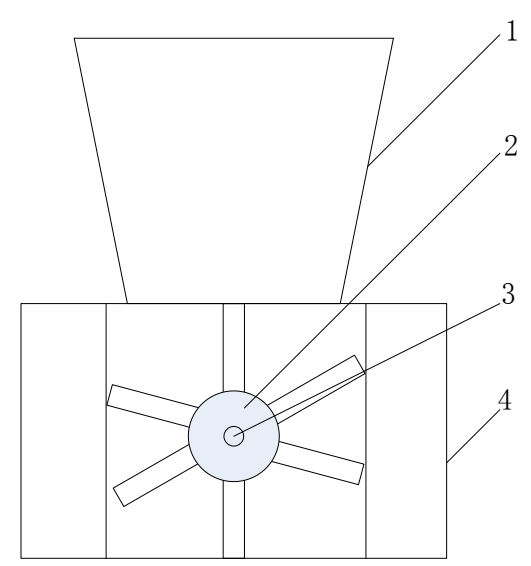

1. Hopper 2.Geneva wheel 3.Shaft 4.Shell, Figure 2.The Geneva wheel feeder

Control system design. Beef cattle feeding control system is designed based on the motion controller in this paper, the motion controller is the core of the control system, motion controller is used to control the blanking machine Geneva motion, receive signals, and according to the input signal do the Geneva motion control. PC serves as the upper computer of the motion controller, completes programming and debugging work. The sensor is used for signal detection. The servo system receives motion command from motion controller, and drive the coordinated movement of various agencies. The motion controller and other hardware integration is shown in figure 3.

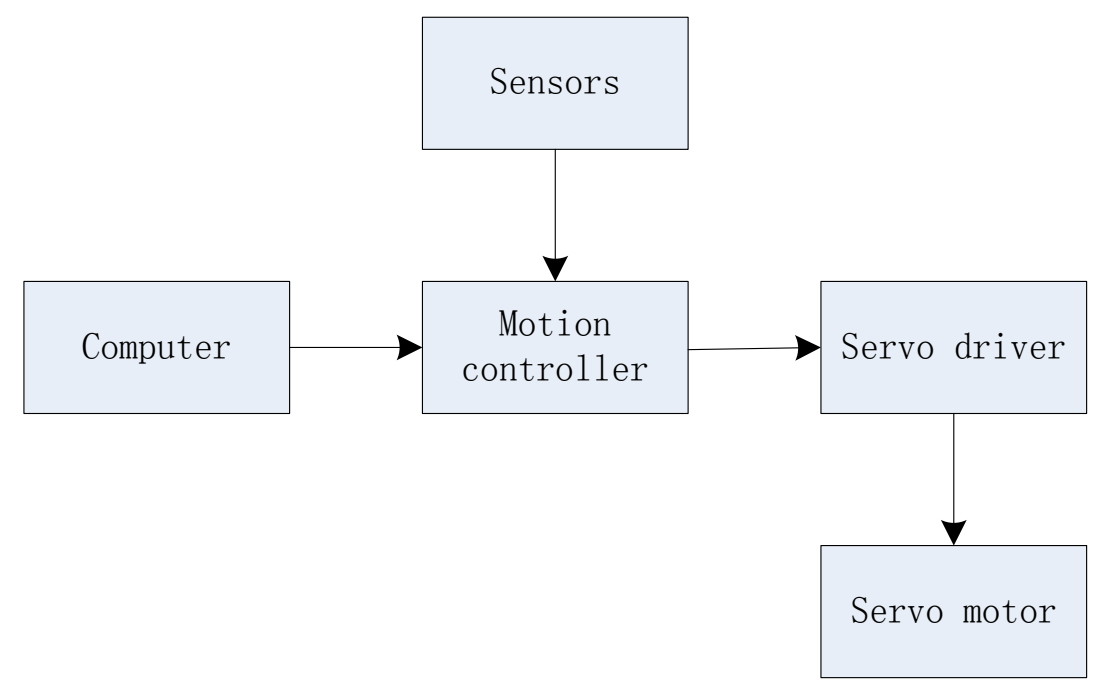

Figure 3.The hardware integration 


\section{Software design}

Software structure design. The motion controller only has develop nuclear, no operation nuclear, so it does not have the ability to do separate programming, it is a kind of open controller based on PC, it also need to complete the program development by PC. As shown in Figure 4, the control system used the form of upper and lower computer in this paper, in the software design, the upper and lower computer performs different tasks. PC as the upper computer is mainly used as programming tools, does the overall program planning and management; motion controller as slave machine is mainly used to perform motion control program. The written procedures can be directly transmitted to the motion controller through the Ethernet, motion controller receives the control program can run the program independently from the computer PC.

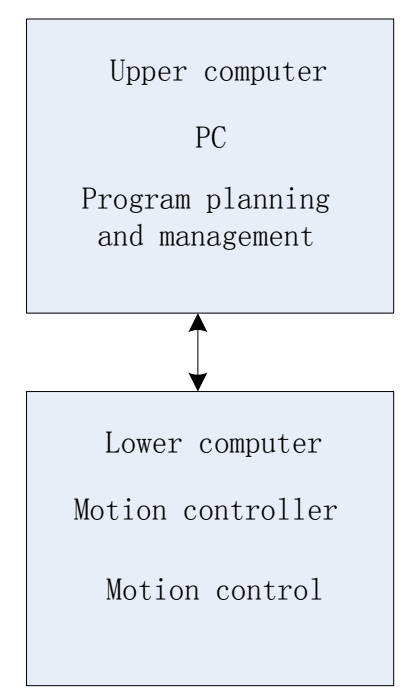

Figure4. Software structure

Program flow design. According to the control requirements of beef cattle automatic feeding system, process of control system is shown in figure 5. The initialization is before the program feeding starting, when the initialization is complete, the operator set feeding quantity and the need for feeding cattle. After the completion of the setting, feeding starts, the system will have feed hopper detection, if the system does not detect feed, it cannot work. When the system detects the feed, the wheel blanking machine works, the motor drives the rotary wheel groove, and complete blanking. The system will automatically detect any fault, if there is the failure, it will stop running, and returns to the initialization program automatically. 


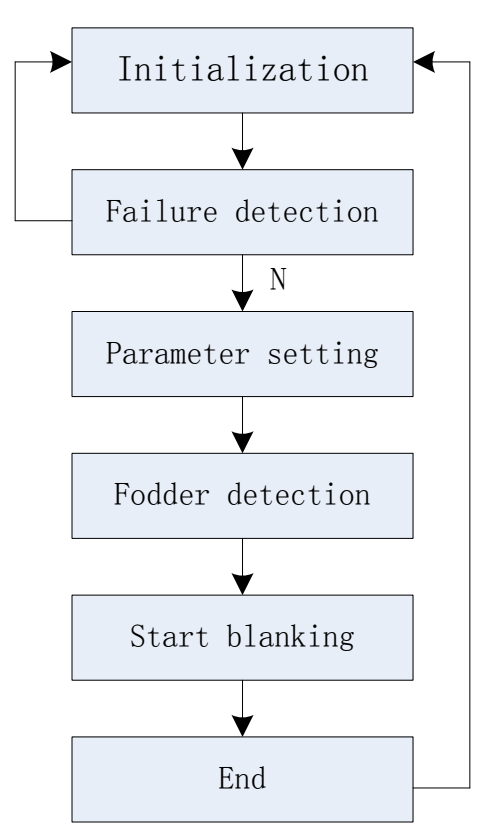

Figure5. Work flow

I/O design. The system sends and receives signal through the $\mathrm{I} / \mathrm{O}$ interface of the controller, the running state of the input and output of the system is completed through the I/O interface, the design of I/O system is shown in table 1.

Table1. System I/O design

\begin{tabular}{c|c|c|c}
\hline \multicolumn{2}{c|}{ Input } & \multicolumn{2}{c}{ Output } \\
\hline IN0 & $\begin{array}{c}\text { Feed detection } \\
\text { photoelectric } \\
\text { switch }\end{array}$ & OUT0 & Indicator light 1 \\
IN1 & $\begin{array}{c}\text { Geneva wheel } \\
\text { photoelectric } \\
\text { switch }\end{array}$ & OUT1 & Indicator light 2 \\
\hline IN2 & $\begin{array}{c}\text { State detection } \\
\text { photoelectric } \\
\text { switch }\end{array}$ & OUT2 & Indicator light 3 \\
\hline & & OUT3 & Indicator light 4 \\
\hline
\end{tabular}

\section{Precision test}

After the beef automatic feeding system is designed, precision test must be carried on to compare the quantity of the material the precision blanking and the actual number. The results are shown in Table 2 , the results show that the system can realize the automation of feeding beef cattle feeding, it has good reliability, and high efficiency. It can replace the manual feeding, and it has an important significance to the development of beef cattle industry.

Table2. Precision test results ( $\mathrm{kg})$

\begin{tabular}{c|c|c|c|c|c|c}
\hline $\begin{array}{c}\text { Target } \\
\text { value }\end{array}$ & A1 & A2 & A3 & A4 & A5 & Average value \\
\hline 3 & 2.85 & 2.91 & 2.95 & 2.88 & 2.90 & 2.898 \\
\hline 4 & 3.91 & 3.95 & 3.89 & 3.91 & 3.88 & 3.908 \\
\hline 5 & 4.92 & 4.88 & 4.86 & 4.96 & 4.90 & 4.904 \\
\hline
\end{tabular}




\section{Summary}

In this paper, aiming at the problem of low efficiency and higher cost in original beef cattle feeding industry, an automatic feeding system is designed based on motion controller, the automatic feeding system can be achieved in beef cattle feeding. Using the motion controller can improve the system flexibility and scalability. The modular design can be personalized configuration of the feeding quantity, the precision of experiment of automatic feeding system is done, the result proves that the system is feasible, which can improve the working efficiency and reduce the production cost, it is applied to the beef cattle industry, it has a certain practical value.

\section{Acknowledgement}

This research was financially supported by the National Science Foundation.

\section{References}

[1] Zhang Yayi, Li Xuejiao, Cao Qiong. development of cattle breeding situation and Countermeasures of small size [J]. Modern agricultural science and technology, 2013, (1): 250-252.

[2] Liu Taiyu, Geng Fanjun, Liu Yang. The Chinese beef industry present situation and Development Countermeasures [J]. Cattle magazine, 2003, 29 (2): 62-64.

[3] Zhao Yongliang. Beef cattle breeding management [J]. Animal husbandry and feed science, 2010, 31 (1): 125-125.

[4] Li Qiang, Zhu Yueming. The problems and solutions of the process of feeding beef cattle [J]. Science in China, 2011, 37 (6): 64-66. 